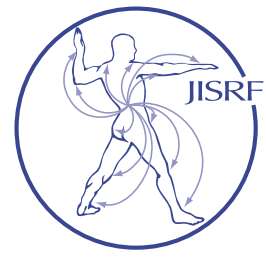

\title{
Periprosthetic Distal Femur Fractures: Review of Current Treatment Options
}

Head $J^{1}$

\section{Abstract}

The geriatric population in general and specifically recipients of total knee arthroplasty (TKA) have increasing functional demands along with an increasing life expectancy. Certain intraoperative aspects of the index procedure, revision TKA, or the patient's physiology (i.e.- osteoporosis, rheumatoid arthritis, neurologic disease) predispose the patient to post-operative periprosthetic distal femur fractures (PDFF). This review describes the epidemiology, classification, examination, and treatment options of PDFF. Osteoporosis and intraoperative anterior femoral cortex notching are primary patient and surgeon specific factors, respectively. The two most commonly used classification systems were described by Rorabeck and Kim and should be used to guide the surgeon's choice of treatment. The non-operative treatment of PDFF is rare, requires close radiographic follow up, and delayed union is common. Open reduction with internal fixation (ORIF) is best accomplished with minimally invasive techniques and distal locking screws. Retrograde, intra-medullary nail fixation is technically difficult, but provides earlier weight bearing and comparable time to union as ORIF. Revision TKA is indicated in patients with adequate bone stock, a simple fracture pattern without ligamentous instability, and a loose or malaligned femoral component. Allograftprosthetic composite (APC) or distal femoral replacement (DFR) is indicated for patients presenting with a PDFF about poor or deficient bone stock. Patients with PDFF present a challenge to the arthroplasty surgeon in regards to choice of treatment and increased morbidity and mortality post-operatively. Close follow up is required and fracture union is often delayed.

\section{Background}

Total knee arthroplasty (TKA) is one of the most commonly performed, elective orthopedic procedure in the United States; with an estimated 4.7 million living recipients in the United States [1]. As patients' average life expectancy and functional demands increase, the number of patients who undergo TKA will increase and, hence the incidence of serious post-operative complications, including periprosthetic distal femur fractures (PDFF), will likely increase proportionately.

Periprosthetic fractures about a total knee, occurring intraoperatively or postoperatively, present a challenge to the surgeon. Multiple host factors including osteoporosis and other comorbidities (ie. poor bone stock, quality of previous implant fixation) affect treatment options [르, $\underline{3}$. Additionally, the fracture pattern may disrupt ligamentous attachments of the distal femur, causing instability of the knee and require the use of a constrained prosthesis [4]. Multiple options exist for treatment of PDFF and the general orthopedic surgeon should be well versed in the optimal fixation paradigm for a particular fracture pattern. The purpose of this review is to define the epidemiology, pathogenesis, and classification of PDFF, review the literature regarding fixation strategies, and suggest a treatment algorithm to aid in surgical planning.

Keywords: total knee, complication, periprosthetic fracture, revision total knee, osteoporosis, femoral notching Level of Evidence: AAOS Therapeutic Level III Educational Value \& Significance: JISRF Level B 


\section{Epidemiology}

Among distal femur periprosthetic fractures, the supracondylar region is most commonly affected and has been reported to occur in $0.3 \%$ to $2.5 \%$ after primary TKA and $1.6 \%$ to $38 \%$ after revision TKA $[\underline{3}, \underline{5}, \underline{6}, \underline{7}, \underline{8}, \underline{9}]$. However, these data likely underestimate the true incidence as many fractures go unnoticed or are treated non-operatively and subsequently not reported. Numerous host factors predispose patients to PDFF; chief among them is osteoporosis. An estimated 9 million osteoporotic fragility fractures occurred in the year 2000 and this specific comorbidity is directly associated with an increased incidence of PDFF $[10,11]$. Meek, et al reported on the Scottish Registry of 4,4511 primary total knees and 3222 revision total knees and identified female sex, age greater than 70, and revision surgery as risk factors for subsequent PDFF [12]. Additionally, rheumatoid arthritis, prolonged steroid therapy, and neurological diseases significantly increase the risk of PDFF $[\underline{7}, \underline{13}, \underline{14}, \underline{15}]$.

Technical aspects of the index procedure may predispose a patient to subsequent PDFF. Shawen, et al., using 13 matched pairs of cadaver femora, demonstrated that a $3 \mathrm{~mm}$ anterior cortical defect (ie- "notching") significantly decreased torsional load to failure and further demonstrated that fracture risk is increased in osteoporotic, notched femora [11]. In another cadaveric biomechanical study, Lesh et al. showed that full-thickness notching of the anterior cortex significantly lessened the load to failure by decreasing the bending strength by $18 \%$ and torsional strength by about $40 \%$ [16]. Interestingly, clinical outcomes that validate these theoretical laboratory findings are lacking and several series have not correlated anterior femoral notching to an increased incidence of subsequent PDFF $[\underline{17}, \underline{18}]$. In a finite element analysis, Conlisk, et al. demonstrated that a well-placed distal femoral implant significantly increased the stresses about the anterior cortex and stresses and strains were dramatically increased in models of osteoporotic bone and when the knee was under increased flexion angles [19]. Considering that approximately $26 \%$ of the United States population over the age of 70 years has a total knee replacement and the concomitant health burden of osteoporosis in this population, it is not surprising that female sex and age over 70 represent significant risk factors to PDFF $[\underline{10}, \underline{12}]$

\section{Classification}

Although many classifications of supracondylar femur fractures have been developed, Lewis and Rorabeck pro- posed their now widely used system based on the original Neer classification. Their classification considers fracture displacement and the stability of the prosthesis in order to guide management and is summarized in table 1 [ $\underline{8}$ ]. Type 1 fractures are non displaced fractures about a stable prosthesis, type 2 fractures are displaced greater than $5 \mathrm{~mm}$ or 5 degrees, but the prosthesis remains stable, type 3 includes displaced and non-displaced fractures about a loose or failing prosthesis secondary to instability or advanced polyethylene wear.

\begin{tabular}{|l|l|l|}
\hline Type & Fracture Description & Component Description \\
\hline 1 & Nondisplaced & Femoral component intact \\
\hline 2 & Displaced $>5 \mathrm{~mm}$ or $5^{\circ}$ & Femoral component intact \\
\hline 3 & $\begin{array}{l}\text { Nondisplaced or } \\
\text { Displaced }\end{array}$ & $\begin{array}{l}\text { Femoral component loose or } \\
\text { failing }\end{array}$ \\
\hline
\end{tabular}

Table 1. PDFF classification proposed by Lewis and Rorabeck. The fracture is described as nondisplaced if less than $5 \mathrm{~mm}$ translation or 5 o angulation. Femoral component stability is based on radiographic evidence of osteolysis, indicating a loose or failing prosthesis.

An alternative classification proposed by Kim, et al (table 2) considers the bone quality, ability to reduce the fracture, and the position and quality of fixation of the femoral prosthesis, thereby guiding management [20] Type 1 fractures occur in a stable, well-aligned prosthesis; type 1A are non-displaced or reducible fractures treated by closed means while type 1B are irreducible and require open reduction and internal fixation. Type 2 fractures are reducible with good bone stock but a loose or maligned component, which requires revision arthroplasty with a long stemmed component. Type 3 fractures are severely comminuted with poor distal bone stock with a loose and maligned component and necessitate the use of a distal femoral replacement.

\begin{tabular}{|l|l|l|l|}
\hline Type & $\begin{array}{l}\text { Fracture } \\
\text { Description }\end{array}$ & Bone Quality & $\begin{array}{l}\text { Component } \\
\text { Description }\end{array}$ \\
\hline 1A & $\begin{array}{l}\text { Nondisplaced or } \\
\text { easily reducible }\end{array}$ & Good bone stock & $\begin{array}{l}\text { Stable femoral } \\
\text { component }\end{array}$ \\
\hline 1B & $\begin{array}{l}\text { Require open } \\
\text { reduction }\end{array}$ & Good bone stock & $\begin{array}{l}\text { Stable femoral } \\
\text { component }\end{array}$ \\
\hline 2 & $\begin{array}{l}\text { Nondisplaced or } \\
\text { easily reducible }\end{array}$ & Good bone stock & $\begin{array}{l}\text { Unstable femoral } \\
\text { component }\end{array}$ \\
\hline 3 & $\begin{array}{l}\text { Severe } \\
\text { comminution }\end{array}$ & Poor bone stock & $\begin{array}{l}\text { Unstable femoral } \\
\text { component }\end{array}$ \\
\hline
\end{tabular}

Table 2. PDFF classification by Kim, et al. This system utilizes the patient's bone stock, ease of fracture reduction, and component stability in order to guide treatment. 


\section{Examinations}

Initial workup of PDFF includes standard anteroposterior and lateral knee radiographs that include views of the entire length of the femur. Scrutiny of the implants for any signs of loosening or migration is essential and includes identification of any radiolucencies at the bone/cement/ implant interfaces and comparison to any available previous radiographs. If signs of loosening and osteolysis are noted, then a thorough infectious workup to include: serological markers (ESR and CRP) and preoperative joint aspiration with with synovial white cell count (WCC), polymorphonuclear (PMN) cell proportion and microbiological analysis. In a recent prospective study, the Alpha-defensin immunoassay test was found to have a sensitivity of $97 \%$ and specificity of $97 \%$ for diagnosing periprosthetic joint infection and is now recommended to be included in the workup [21]. Antecedent knee or thigh pain may indicate pre-existing component loosening and should be included in the history. Further studies include CT to characterize the fracture pattern, evaluate bone stock, and evaluate the implant's relationship to the fracture.

\section{Treatment}

\section{Non-operative treatment}

Rarely, non-operative treatment can be considered for stable fractures with minimal displacement, good host bone stock, and a well-fixed and well-aligned component, i.e. Type 1 fractures $[\underline{20}, \underline{22}]$. These fractures comprise the minority of presentations, as the deforming forces about the knee cause angular deformity and displacement; with the typical pattern of the the distal fragment aligned in varus, adduction, and internal rotation []ㅡ.

Stable fractures of the distal femur with acceptable alignment can be managed with cast or brace immobilization and protected weight bearing, followed by range of motion exercises [23]. Close radiographic observation is required and surgical intervention may be necessary if subsequent displacement is observed. The surgeon must be prepared for prolonged healing, with some fractures taking up to 4 months to demonstrate stable union []․ In a comparison study of $61 \mathrm{PPDF}$ in 58 patients with mean follow up of 3.7 years, Culp et al treated 31 fractures in 30 patients with operative treatment and 30 fractures in 28 patients conservatively with casting or traction. The group treated conservatively had a higher malunion and nonunion rate (46\%) than the group treated surgically (13\%). Ambulatory status was negatively affected following conservative treatment, with $50 \%$ of patients seeing a change.
The surgical fixation group saw $13 \%$ of patients' ambulation affected following treatment []].

\section{Operative treatment}

When indicated, surgical planning is guided by implant stability, fracture pattern, presence of infection, and periprosthetic bone stock. The goal of stable fixation is to restore limb length, maintain anatomic alignment, ensure proper axial rotation, and allow for early mobilization. $\mathrm{Pa}-$ tient optimization is paramount in order to minimize morbidity and mortality. In cases with a stable femoral prosthesis without evidence of infection, ORIF or treatment with an intramedullary implant is indicated. If implant instability, septic joint, or osteomyelitis is suspected, then revision arthroplasty is the treatment of choice.
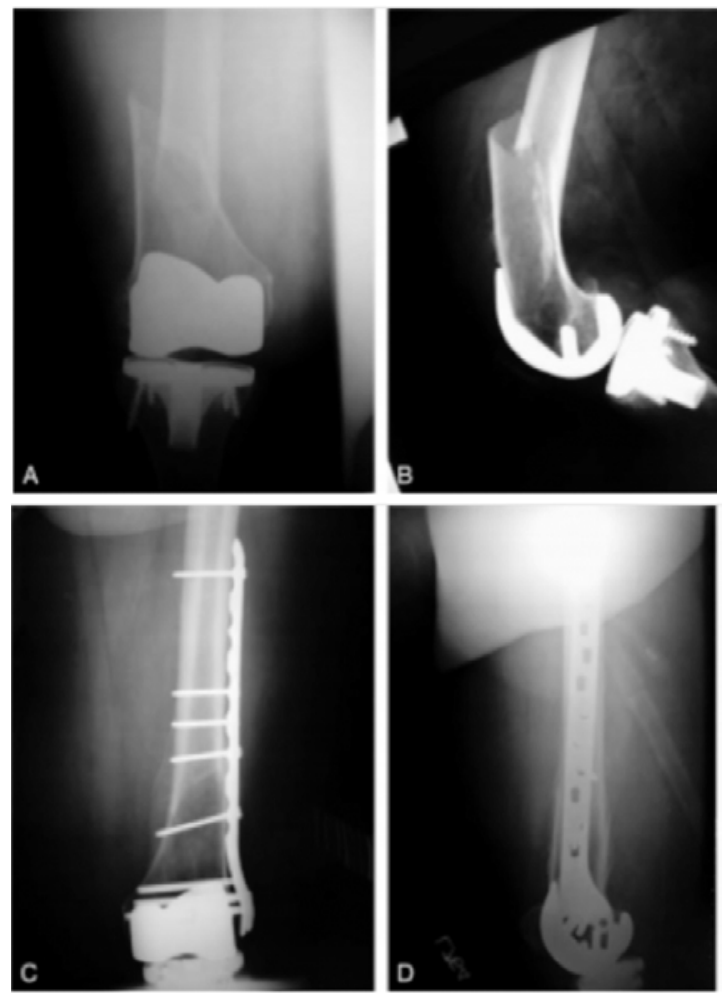

Figure 1. Radiographs showing successful distal locking plate ORIF treatment of a supracondylar periprosthetic femur fracture above a stable total knee arthroplasty (Lewis and Rorabeck 2, Kim $1 B)$. A, Injury AP view. $B$, Injury lateral view. $C, D, A P$ and lateral views at 12-month follow-up show a healed fracture with acceptable alignment. (From Ricci, et al, J Orthop Trauma. 2006;20:190-196).

\section{Open Reduction Internal Fixation}

Of the two options available to the surgeon, locking plates have seen reproducible results with good or excellent outcomes compared to conventional plate technology. Recently, locking plates have completely replaced angled blade plates (ABP) and dynamic condylar screws (DCS). This is due to the former having better outcomes in osteoporotic bone with comminution, limiting soft tissue com- 
promise with minimally invasive instrumentation, and available polyaxial screw options that specific fragment fixation $[\underline{24}, \underline{25}, \underline{26}, \underline{27}, \underline{28}]$. Figure 1 shows a PDFF amenable to repair with ORIF [27].

In a cohort study, Hassan et al demonstrated a satisfactory union in $96 \%$ of patient treated with locking plates. The authors cautioned against allowing full weight bearing until 3 months post-op and noted that delayed union up to 6 months may be observed [르] . In a case control study of 12 patients, Norrish et al demonstrated union in 11 of 12 PDFF treated with the LISS (Less Invasive Stabilization System, Synthes USA, West Chester, PA) implant. Mean time to union was 3.7 months [잉. Streusel et al compared PDFF fixation with distal femoral locking plates in fractures proximal to the femoral component in 28 patients and in 33 patients where the fracture propagated distal to the well-fixed component. No difference was observed in malunion, nonunion, delayed healing, hardware failure, or infection; thus demonstrating the utility of locking screws in extreme distal PDFF [31]. Importantly, the use of minimally invasive techniques have demonstrated higher union rates, earlier return to pre-injury functional status, and fewer soft-tissue complications $[\underline{26}, \underline{32}, \underline{33}]$.

\section{Intramedullary (IM) Nail Fixation}

Load-sharing IM nails are an attractive fixation option for PDFF. These rigid, load sharing devices offer stable fracture fixation with preserved soft tissue envelope with quicker return to weight-bearing and fewer union complications than ORIF $[\underline{34}, \underline{35}, \underline{36}]$. Important to the pre-operative plan is using a compatible IM nail in regards to the intercondylar distance and anterior to posterior position of the femoral component notch. Thompson et al produced a convenient reference table for popular TKA designs with nail compatibility [37]. Often, the notch forces the starting point of a retrograde nail posterior to Blumensaat's line and inherently predisposes to recurvatum deformity and malalignment [ $\underline{38}]$. A representation of this treatment option and the characteristic post-operative deformity is shown in figure 2 .

There is a paucity in the literature comparing cohorts treated with laterally-based locking plates to IM nail fixation. In a study of 91 patients, 29 were treated with an IM rod while 66 received periarticular locking plates. A trend toward nonunion was observed in the locked plating group, 19 vs $9 \%$ in the IM nail group. The study observed no difference in time to successful union. Radiographically, no difference in femoral flexion, extension, or fracture translation, and an equal trend toward valgus alignment was observed [36]. In a small, retrospective study, Kiliçoğlu et al demonstrated no difference in the time to
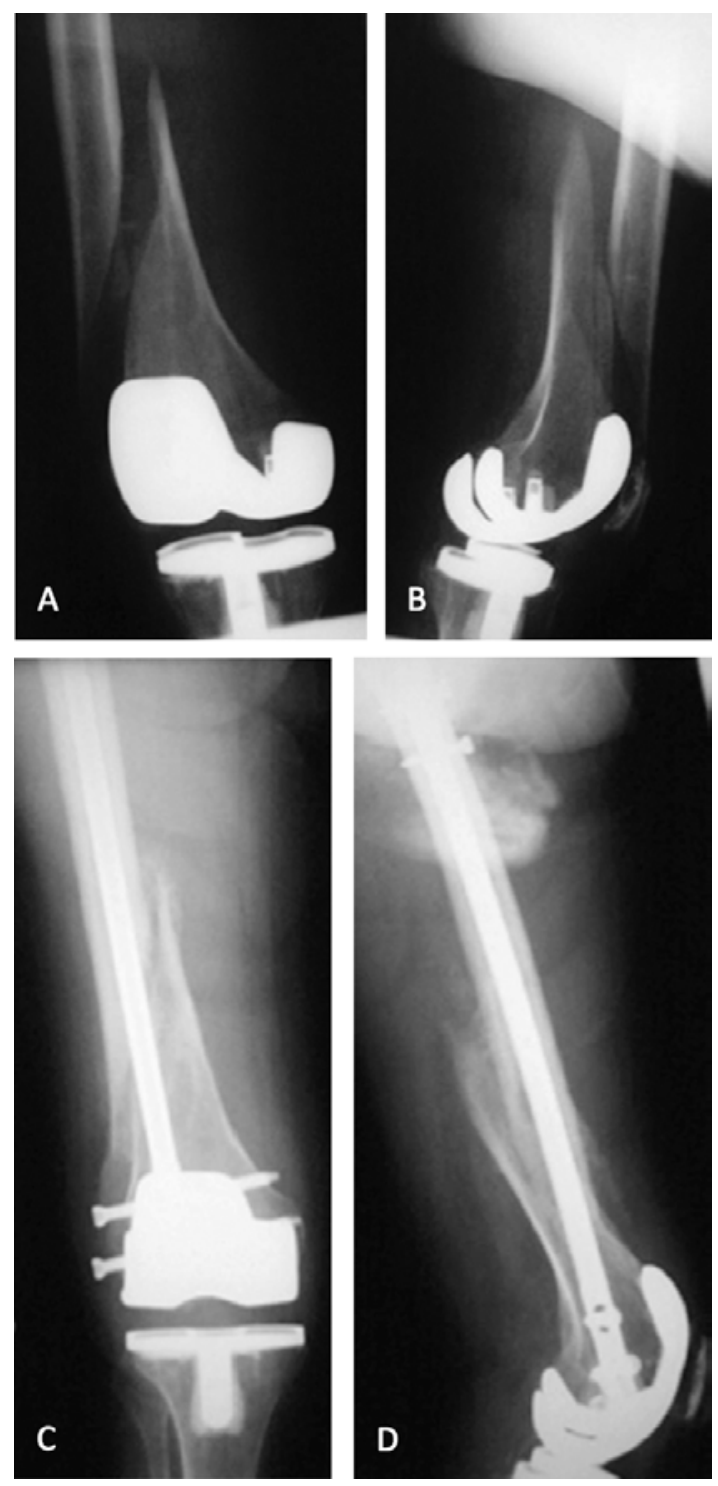

Figure 2. A, B, AP and lateral radiographs demonstrating a long, spiral PDFF with a stable femoral implant (Lewis and Rorabeck 2, Kim IB). C D, Postoperative radiograph showing treatment with a retrograde, interlocking intramedullary nail and characteristic extension of the distal fragment due to the femoral component forcing the starting point posterior.

union, range of motion, Knee Society Score or sagittal and coronal alignment when retrograde IM nailing was compared with ORIF with locking plates [풀.

Several limitations exist for this technically challenging surgical option. Insertion of a retrograde IM nail risks joint infection secondary to the necessary arthrotomy. Secondly, the size of the fracture fragments precludes use in severe comminution and should only be utilized for large distal fragments. Further, IM nailing cannot be used in patient's with a posterior stabilized total knee implants due to the closed intracondylar box [40]. IM nail fixation requires a diaphyseal fit for stability, thus long, proximally locked nails are required. The presence of an ipsilateral to- 
tal hip arthroplasty creates a possible stress riser between implants and bridging may be required if this situation is present.

\section{Revision Total Knee Arthroplasty}

Revision TKA is indicated in patients with adequate bone stock, a simple fracture pattern without ligamentous instability, and a loose or malaligned femoral component [41]. This corresponds to a Rorabeck type 3 and a Kim type 2. Utilization of an uncemented long-stemmed femoral component with indicated fracture fixation using interfragmentary screws and small plates is preferred, as this construct allows for early weightbearing [42]. Preoperative walking ability, range of motion, and early post-op rehabilitation were the primary determinants of a good outcome in the Cordeiro et al study of revision TKA in 5 of 10 patients presenting with PDFF [43]. Srinivasan et al. reported on 6 PDFF and 2 complex native distal femur fractures treated with long-stem femoral components. The most common complication was a mean loss of 7.7 degrees of flexion; highlighting the importance of early mobilization in this group. Mean time to fracture union was 3.8 months [42].

Patients presenting with a PDFF about poor or deficient bone stock pose a challenge to the surgeon and two options exist for treatment: allograft-prosthetic composite (APC) or distal femoral replacement. These treatment methods may also be required for nonunion following previously failed attempt at fracture fixation via ORIF or IM nail fixation. Concern for early loosening of highly constrained implants in young, active patients may lead the surgeon to treatment with an APC. This involves the subperiosteal excision of the deficient distal femur while retaining the soft tissue sleeve of collateral ligaments and implantation of a stemmed, semi-constrained TKA. In a review of 9 patients treated with APC for PDFF, Kassab et al. noted union without migration or loosening at mean follow-up of 6 years [44.]. In 68 patients treated with APC, 17 for PDFF, Backstein et al. reported one nonunion, two fractures through allograft, and four deep infections. They also noted a $14.8 \%$ revision rate at 5.4 years [45].

For low-demand patients or patients having failed previous fixation or reconstruction methods, revision with a distal femoral replacement (DFR) is an option. Although new implant designs give increased freedom of rotation, thus decreasing the bone-prosthesis stress, this should be seen as a limb salvage procedure. Berend and Lombardi reviewed 39 rotating-hinged DFR devices used a cohort of 37 patients, including 13 PDFF cases. There was no incidence of aseptic loosening at mean follow up of 46 months with $87 \%$ survivorship. There were five reoperations, including two patients with recurrent infection after two-stage treat- ment, one patient with a periprosthetic fracture treated by open reduction and internal fixation, one patient with late hematogenous infection, and one patient with bearing exchange to treat hyperextension [46].

In a review of 22 PDFF in 20 patients with a mean age of 69.5 and 58.6 months follow up, Mortazavi et al. showed a high complication rate of $22.3 \%$ requiring additional surgery. One patient had refracture with subsequent nonunion, a second fracture between the stems of the DFR and THA, a third sustained a subtrochanteric fracture above the DFR stem, the fourth developed a femoral neck and intertrochanteric fracture of the ipsilateral hip 2 months after the index revision knee surgery, and the fifth patient developed a hematoma 10 days after surgery, which was drained in the operating room. He then presented with a fracture of femoral stem 34 months after the index revision surgery. The authors caution use of DFR as a last resort where alternative treatment options are not possible [47]. Figure 3 demonstrates the clinical course of this patient.
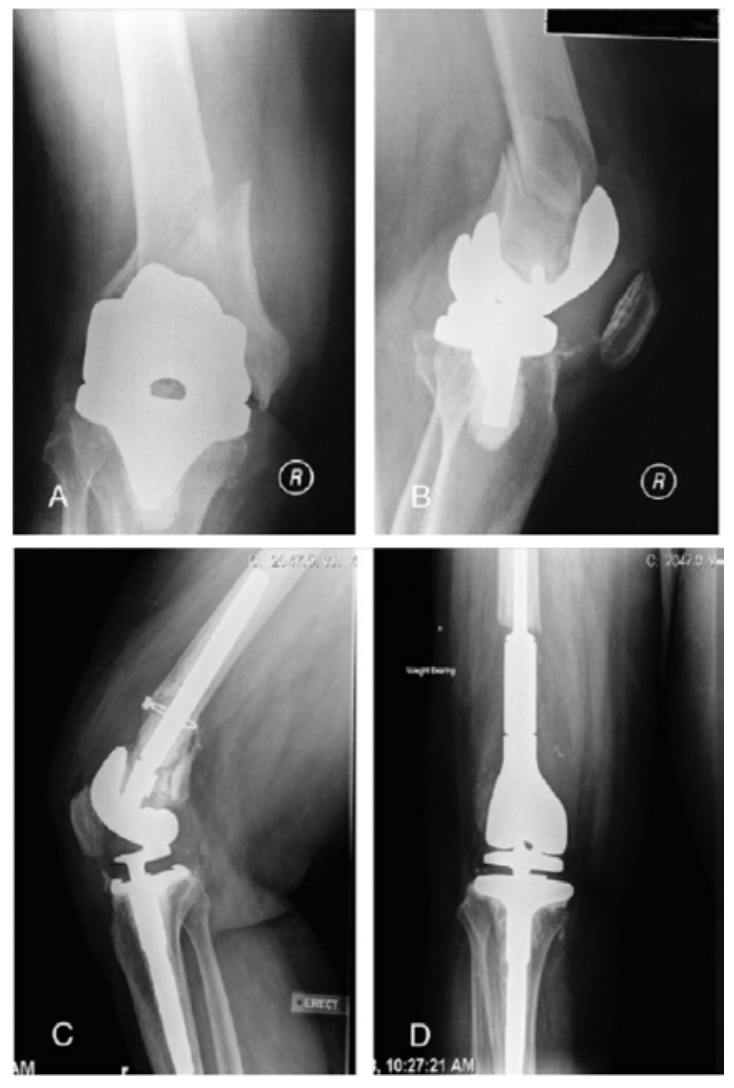

Figure 3. A, B, AP and lateral radiographs of a PDFF about an unstable femoral component in a patient with good bone stock (Lewis and Rorabeck 3, Kim 2). C, demonstrates distal femoral replacement stem fracture at 34 months post-op necessitating revision with distal femoral replacement, D. (From Mortazavi, et al, J Arthroplasty 2010; 25:775-780.)

Few comparison studies exist with matched cohorts, but Saidi et al. present 23 patients; 7 treated with APC, 9 
patients received revision TKA systems (RSA), and 7 patients had DFR. Operative time and blood loss were significantly less in RSA and DFR and shortest average hospital stay (6.4 days) was in the DFR group. No difference was observed in the 6 week or 6 month Knee Society Scores [4]. These results highlight the possibility that low-demand patients can be successfully treated with DFR without an increased complication rate.

\section{Complications}

The associated morbidity and mortality of PDFF are very high and carry a greater risk than native distal femoral fractures [48]. Mortality of up to $17 \%$ at 6 months and $30 \%$ at 1 year have been reported $[\underline{49}, \underline{50}, 51]$. Postoperative mobility of patients is of utmost importance and many patients will require long-term ambulatory assistance. Fracture union is often delayed in these patients and close follow up is required $[\underline{6}, \underline{29}]$. If nonunion is of specific concern due to host factors, indirect reduction techniques and sub muscular plating or DFR should be chosen $[\underline{46}, \underline{52}]$. Patient specific complications include extensor mechanism disruption, infection, and implant failure. Complications of prolonged immobility are respiratory tract infections, thromboembolism, pressure ulcers, mental status changes, and urinary tract infections.

\section{Conclusions}

PDFF present a challenge to the arthroplasty surgeon. The decision of ORIF versus revision arthroplasty should be made in the context of the patient's pre-injury physiologic and anatomic status. Early mobilization, early union, and respect for soft tissue integrity are paramount concerns. A suggested treatment algorithm based on the Rorabeck and Kim classifications and literature review is presented in figure 4.

\section{References:}

1. Maradit Kremers H, Larson DR, Crowson CS, et al. Prevalence of Total Hip and Knee Replacement in the United States. The Journal of Bone and Joint Surgery American volume. 2015;97(17):1386-1397. doi:10.2106/JBJS.N.01141.

2. Bezwada HP, Neubauer P, Baker J, et. al. Periprosthetic supracondylar femur fractures following total knee arthroplasty. J Arthroplasty. 2004;19: 453-458.

3. Figgie MP, Goldberg VM, Figgie HE III, et. al. The result of treatment of supracondylar fracture above total knee arthroplasty. J Arthroplasty. 1990; 5:267-276.

4. Saidi KM, Ben-Lulu O, Tsui M, Safir O, Gross AE, Backstein D. Supracondylar Periprosthetic Fractures of the Knee in the Elderly Patients: A Comparison of Treatment Using Allograft-Implant Composites, Standard Revision Components, Distal Femoral Replacement Prosthesis. J Arthroplasty. 2014;1: 110 - 114.

5. Dennis DA. Peri-prosthetic fractures following total knee arthroplasty. J Bone Joint Surg. 2001; 83-A: 120-128.

6. Delport PH, Van Audekercke R, Martens M, Mulier JC. Conservative treatment of ipsilateral supracondylar femoral fracture after total knee arthroplasty. J Trauma 1984; 24: 846-849.

7. Culp RW, Schmidt RG, Hanks G, Mak A, Esterhai JL, Heppenstall RB. Supracondylar fracture of the femur following prosthetic knee arthroplasty. Clin Orthop. 1987; 222:212-222

8. Rorabeck CH, Taylor JW. Periprosthetic fractures of the femur complicating total knee arthroplasty. Orthop Clin North Am. 1999; 30:265-277.

9. Schroder HM, Berthelsen A, Hassani G. Cementless porous coated total knee arthroplasty: 10-year results in a consecutive series. J Arthroplasty. 2001;16:559567.

10. Johnell O, Kanis J. An estimate of the worldwide prevalence and disability associated with osteoporotic fractures. Osteoporosis Int. 2006; 17: 1726-1733

11. Shawen SB, Belmont PJ Jr, Klemme WR, Topoleski LD, Xenos JS, Orchowski JR. Osteoporosis and anterior femoral notching in periprosthetic supracondylar femoral fractures: a biomechanical analysis. J Bone Joint Surg Am 2003;85$\mathrm{A}(1): 115-121$

12. Meek RMD, Norwood T, Smith R, Brenkel IJ, Howie CR. The risk of peri-prosthetic fracture after primary and revision total hip and knee replacement. J Bone Joint Surg [Br] 2011;93-B:96-101.

13. Raab GE, Davis CM 3rd. Early healing with locked condylar plating of periprosthetic fractures around the knee. J Arthroplasty. 2005;20: 984-989.

14. DiGioia AM, Rubash HE: Periprosthetic fractures of the femur after total knee arthroplasty: A literature review and treatment algorithm. Clin Orthop 1991;271:135142.

15. Berry DJ. EPIDEMIOLOGY: Hip and Knee. Clin Orthop. 1999;30:183-190.

16. Lesh ML, Schneider DJ, Deol G, et al. The consequences of anterior femoral notching in total knee arthroplasty. A biomechanical study. J Bone Joint Surg Am 2000;82:1096-1101.

17. Gujarathi N, Putti AB, Abboud RJ, MacLean JG, Espley AJ, Kellett CF. Risk of periprosthetic fracture after anterior femoral notching. Acta Orthop. 2009 Oct;80(5):553-6.

18. Ritter MA, Thong AE, Keating EM, Faris PM, Meding JB, Berend ME, Pierson $\mathrm{JL}$, Davis KE. The effect of femoral notching during total knee arthroplasty on the prevalence of postoperative femoral fractures and on clinical outcome. J Bone Joint Surg Am. 2005;87(11):2411-4.

19. Conlisk N, Howie CR, Pankaj P. An efficient method to capture the impact of total knee replacement on a variety of simulated patient types: A finite element study. Med Eng Phys. 2016 Sep;38(9):959-68.

20. Kim K, Egol KA, Hozack WJ, Parvizi J. Periprosthetic fractures after total knee arthroplasties. Clin Orthop Relat Res. 2006;446: 167-75.

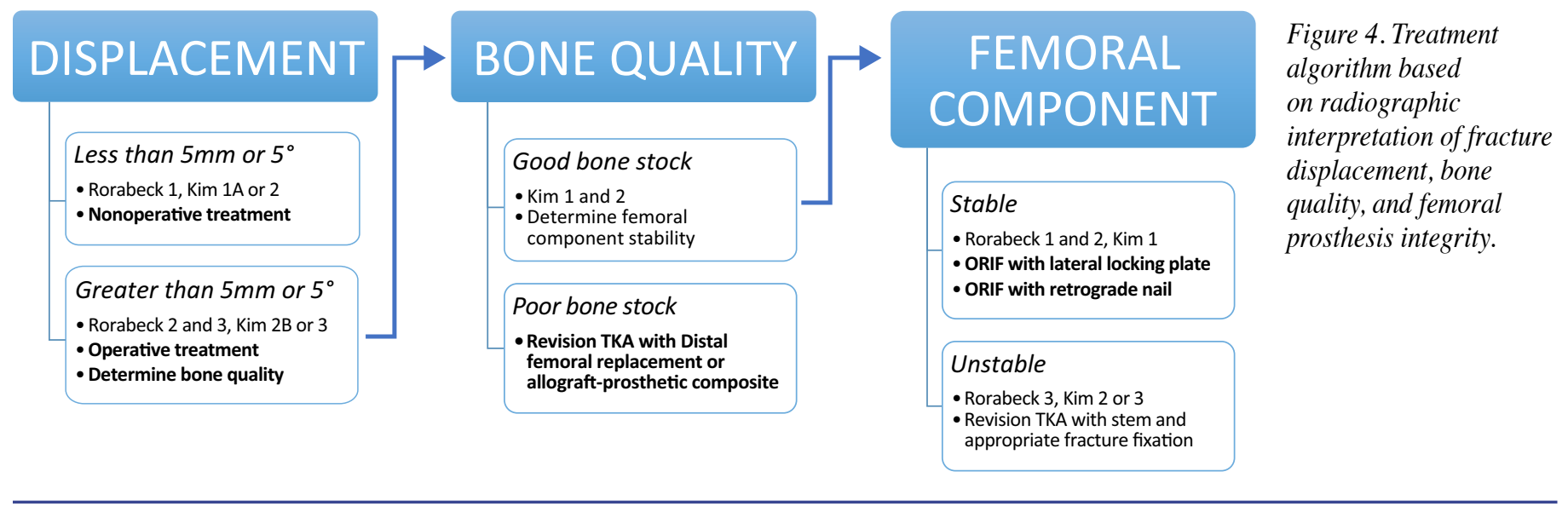

Joint Implant Surgery \& Research Foundation • JISRF.org • ReconstructiveReview.org 
21. Bonanzinga T, Zahar A, Dütsch M, Lausmann C, Kendoff D, Gehrke T. How Reliable Is the Alpha-defensin Immunoassay Test for Diagnosing Periprosthetic Joint Infection? A Prospective Study. Clin Orthop Relat Res. 2016 Jun 24.

22. Merkel KD, Johnson EW Jr. Supracondylar fracture of the femur after total knee arthroplasty. J Bone Joint Surg Am. 1986;68:29-43.

23. Moran MC, Brick GW, Sledge CB, Dysart SH, Chien EP. Supracondylar femoral fracture following total knee arthroplasty. Clin Orthop Relat Res. 1996;324:196209.

24. Egol KA, Kubiak EN, Fulkerson E, et al. Biomechanics of locked plates and screws. J Orthop Trauma. 2004;18:488-93.

25. Kregor PJ, Hughes JL, Cole PA. Fixation of distal femoral fractures above total knee arthroplasty utilizing the Less Invasive Stabilization System (L.I.S.S.). Injury. 2001;32:SC64-SC75.

26. Althausen PL, Lee MA, Finkemeier CG. Operative stabilization of supracondylar femur fractures above total knee arthroplasty: a comparison of four treatment methods. J Arthroplasty. 2003;18:834-839.

27. Ricci WM, Loftus T, Cox C, et al. Locked plates combined with minimally invasive insertion technique for the treatment of periprosthetic supracondylar femur fractures above a total knee arthroplasty. J Orthop Trauma. 2006;20:190-196.

28. Weber D, Peter RE. Distal femoral fractures after knee arthroplasty. Int Orthop. 1999;23:236-9.

29. Hassan S, Swamy GN, Malhotra R, Badhe NP. Periprosthetic fracture of the distal femur after total knee arthroplasty; prevalence and outcomes following treatment. J Bone Joint Surg (Br). 2012;94-B Suppl 24:6.

30. Norrish AR, Jibri ZA, Hopgood P. The LISS plate treatment of supracondylar fractures above a total knee replacement: a case control study. Acta Orthop Belg. 2009;75:642-8.

31. Streubel PN, Gardner MJ, Morphed S, Collinge CA, Gallagher B, Ricci WM. Are extreme distal periprosthetic supracondylar fractures of the femur too distal to fix using a lateral locked plate?. Bone \& Joint J. 2010; 92-B(4), 527-534.

32. Hoffman MF, Jones CB, Sietsema DL, Koenig SJ, Tornetta P. Outcome of periprosthetic distal femoral fractures following knee arthroplasty. Injury. 2012;43:10849.

33. Ehlinger M, Adam P, Abane L, Rahme M, Moor BK, Arlettaz Y. Treatment of periprosthetic femoral fractures of the knee. Knee Surg Sports Traumatol Arthr. 2011:19:1473-89.

34. Pao JL, Jiang CC. Retrograde intramedullary nailing for nonunions of supracondylar femur fracture of osteoporotic bones. J Formos Med Assoc. 2005; 104:54-59.

35. Murrell GA, Nunley JA. Interlocked supracondylar interlocked nails for supracondylar fractures after total knee arthroplasty. A new treatment method. J Arthroplasty. 1995;10:37-42.

36. Meneghini RM, Keyes BJ, Reddy KK, Maar DC Modern Retrograde Intramedullary Nails Versus Periarticular Locked Plates for Supracondylar Femur Fractures After Total Knee Arthroplasty, J Arthroplasty. 2014; 7:1478-1481.

37. Thompson SA, Lindisfarne AE, Bradley N, Solan M. Periprosthetic supracondylar femoral fractures above a total knee replacement: compatibility guide for fixation with a retrograde intramedullary nail. J Arthroplasty. 2014; 29:1639-164.

38. Service BC, Kang K, Turnbull N, Langford J, Haidukewych G, Koval KJ. Influence of femoral component design on retrograde femoral nail starting point. J Orthop Trauma, 2015; 29:380-384.

39. Kilicoglu OI, Akgül T, Sağlam Y, Yazıcıoğlu O. Comparison of locked plating and intramedullary nailing for periprosthetic supracondylar femur fractures after knee arthroplasty. Acta Orthop Belg. 2013;79:417-21.

40. Engh GA, Ammeen DJ. Periprosthetic fractures adjacent to total knee implants. Treatment and clinical results. J Bone Joint Surg Am. 1997;79: 1100-1113.

41. Keeney JA. Periprosthetic total knee arthroplasty fractures: revision arthroplasty technique. J Knee Surg. 2013;26:19-26.
42. Srinivasan K, Macdonald DA, Tzioupis CC, Giannoudis PV. Role of long stem revision knee prosthesis in periprosthetic and complex distal femoral fractures: a review of eight patients. Injury. 2005; 36:1094-1102

43. Cordeiro EN, Costa RC, Carazzato JG, Silva JDS. Periprosthetic fractures in patients with total knee arthroplasties. Cain Orthop. 1990; 252:182-189.

44. Kassab M, Zalzal P, Azores GMS, Pressman A, Liberman B, Gross AE. Management of periprosthetic femoral fractures after total knee arthroplasty using a distal femoral allograft. J Arthroplasty. 2004; 19:361-368.

45. Backstein D, Safir O, Gross A. Management of bone loss: structural grafts in revision total knee arthroplasty. Clin Orthop. 2006; 446:104-112.

46. Berend KR, Lombardi AV. Distal femoral replacement in non tumor cases with severe bone loss and instability. Clin Orthop Relat Res. 2009;467:485-92.

47. Mortazavi SM, Kurd MF, Bender B, Post Z, Parvizi J, Purtill JJ. Distal Femoral Arthroplasty for the Treatment of Periprosthetic Fractures After Total Knee Arthroplasty. J Arthroplasty 2010; 25:775-780.

48. Streubel PN, Ricci WM, Wong A, Gardner MJ. Mortality after distal femur fractures in elderly patients. Clin Orthop Relat Res. 2011;469:1188-96.

49. Christodoulou A, Terzidis I, Ploumis A, Metsovitis S, Koukoulidis A, Toptsis C. Supracondylar femoral fractures in elderly patients treated with the dynamic condylar screw and the retrograde intramedullary nail: a comparative study of the two methods. Arch Orthop Trauma Surg. 2005;125:73-9.

50. Boyd AD,Wilber JH. Patterns and complications of femur fractures below the hip in patients over 65 years of age. J Orthop Trauma. 1992;6:167-74.

51. Dunlop DG, Brenkel IJ. The supracondylar intramedullary nail in elderly patients with distal femoral fractures. Injury. 1999;30:475-84

52. Bolhofner BR, Carmen B, Clifford P. The results of open reduction and internal fixation of distal femur fractures using a biologic (indirect) reduction technique. J Orthop Traum. 1996;10:372-7.

\section{SUBMISSION HISTORY}

Submitted June 23, 2017

Reviewed August 21, 2017

Revised October 25, 2017

Accepted November 14, 2017

Published December 31, 2017

\section{AUTHOR AFFILIATIONS}

1 Justin M Head, DO

Genesys Regional Medical Center, a Michigan State University Statewide Campus, One Genesys Parkway, Grand Blanc, MI 48439

(Direct inquires to Justin M Head, justin.head8@gmail.com)

\section{AUTHOR DISCLOSURES}

The authors declare that there are no disclosures regarding the publication of this paper.

\section{COPYRIGHT \& OPEN ACCESS}

(C) 2017 Head. All rights reserved.

Authors retain copyright and grant the journal right of first publication with the work. Reconstructive Review is an open access publication and follows the Creative Commons Attribution-NonCommercial CC BY-NC. This license allows anyone to download works, build upon the material, and share them with others for non-commercial purposes as long as they credit the senior author, Reconstructive Review, and the Joint Implant Surgery \& Research Foundation (JISRF). An example credit would be: "Courtesy of (senior author's name), Reconstructive Review, JISRF, Chagrin Falls, Ohio". 